CLINICAL STUDY

\title{
Cancer risk in hyperprolactinemia patients: a population-based cohort study
}

\author{
Katarina Berinder ${ }^{1}$, Olof Akre ${ }^{2}$, Fredrik Granath ${ }^{2}$ and Anna-Lena Hulting ${ }^{1}$ \\ ${ }^{1}$ Endocrine and Diabetes Unit, Department of Molecular Medicine and Surgery and ${ }^{2}$ Clinical Epidemiology Unit, Department of Medicine, Karolinska \\ Institutet, SE-171 76 Stockholm, Sweden
}

(Correspondence should be addressed to K Berinder; Email: katarina.berinder@karolinska.se)

\begin{abstract}
Objective: Experimental evidence indicates that prolactin might play a role in tumorigenesis of several human cancers, but data on cancer risk in hyperprolactinemia patients are sparse. The aim of this study was to investigate cancer risk in hyperprolactinemia patients.

Design: A population-based matched cohort study in Sweden.

Methods: The hyperprolactinemia cohort consisted of patients hospitalized for hyperprolactinemia from 1987 to 1995 identified in the National Patient Register $(n=585)$ and a hospital cohort of prolactinoma patients at Karolinska University Hospital $(n=384)$. For each patient, ten matched individuals were identified via the Register of Population. Cancer occurrence was ascertained via the Swedish Cancer Registry. Hazard ratios (HRs) were estimated by Cox proportional hazards regression. Results: Seventy-three malignant tumors were identified in the hyperprolactinemia patients and 660 tumors in the comparison group (HR 1.31; 95\% confidence interval (CI): 1.02-1.68), mainly attributed to an increased risk of upper gastrointestinal cancer in both males and females (HR 3.69; 95\% CI: 1.70-8.03) and hematopoietic cancer in females (HR 3.51; 95\% CI: 1.06-11.6). Twelve breast cancers occurred in the female patients, corresponding to an HR of 1.09 (95\% CI: 0.60-1.99). Prostate cancer risk in hyperprolactinemia men was reduced (HR 0.40; 95\% CI: 0.16-0.99). Conclusions: An increased overall cancer risk was found in hyperprolactinemia patients, but no increased risk of breast cancer in women and a reduced risk of prostate cancer in men. These findings warrant further investigations and to be confirmed in larger studies but may indicate the importance of an active treatment strategy and follow-up of hyperprolactinemia patients.
\end{abstract}

European Journal of Endocrinology 165 209-215

\section{Introduction}

Prolactin (PRL) is mainly secreted from the lactotroph cells in the anterior pituitary, but is also produced in extrapituitary sites, including the mammary gland, placenta, uterus, prostate, brain and in the immune cells where it may act as an autocrine or paracrine factor (1). Hyperprolactinemia is a common finding in clinical endocrinology and prolactinomas are the most common type of pituitary tumor (2). The first-line treatment of hyperprolactinemia is dopamine agonists, which are highly effective in normalizing PRL levels and reducing tumor size (3). Nevertheless, patients with hyperprolactinemia might be exposed to high levels of PRL for several years because of a delay in diagnosis (4), or in a few cases, treatment failure.

Experimental studies have reported that PRL induces proliferation of breast cancer cells in vitro and enhances growth of mammary carcinoma in rodents and may act as an autocrine or paracrine factor within mammary tissue $(5,6)$. Furthermore, several case reports of breast carcinomas in women and men with prolactinomas have been reported (7-9) raising the issue of whether high PRL levels are associated with an increased risk of breast cancer. Some observational studies have supported such an association $(10,11)$, however, these studies evaluated the risk of breast cancer associated with PRL levels within the normal range (top versus bottom quartile range). In a recent study of patients with treated hyperprolactinemia no increased breast cancer risk was found (12).

Other tumor types may also be affected by PRL. For instance, experimental data have indicated that PRL stimulates prostate cell proliferation and regulates prostate growth and thus may theoretically affect carcinogenesis in the prostate $(13,14)$. However, the role of PRL in human prostate pathology is not clarified and epidemiological data on PRL and risk of prostate cancer is sparse $(15,16)$. Furthermore, it has been suggested that locally produced PRL could play a role in tumor development in gynecological (17), colorectal (18), tongue (19), and hematopoietic cancer $(20,21)$.

According to current treatment guidelines, patients with asymptomatic non-tumoral hyperprolactinemia 
may be left untreated in postmenopausal women or if fertility is not an issue (3). We however, lack long-term follow-up data on the potential risks associated with elevated PRL levels. In this study, we therefore assessed the overall relative risk of cancer and risk of some specific a priori specified cancer forms in a cohort of 969 women and men with hyperprolactinemia.

\section{Materials and methods}

\section{Settings}

All Swedish residents alive in 1947 onwards have been assigned a ten-digit personal identity number, a unique personal identifier referred to in all medical records and official registers (22). Through the use of the personal identity number, it is possible to link information between different databases.

In 1964, the Swedish National Board of Health and Welfare started collecting data on hospital discharge diagnoses in the National Patient Register, and since 1987, the register has complete national coverage. The Swedish Cancer Register was established in 1958 and obtains mandatory reported data from both clinicians and pathologists on all newly diagnosed malignant neoplasms. Information on the site and histopathological features of the tumors is recorded. The Cancer Registry is estimated to be more than $95 \%$ complete (23). Finally, the Register of Population, kept by Statistics Sweden, contains the official Swedish population data, including dates of death and migration. Such population data have been available since 1960.

\section{The cohorts}

Hospital cohort We identified all patients, both men and women $(n=384)$, diagnosed with a prolactinoma between 1974 and 2005 at the Department of Endocrinology, Metabolism and Diabetology, Karolinska University Hospital, Sweden using the clinic's own register of diagnosis. This diagnosis registry was complete from 1993 and thus comprises incident cases (Hospital cohort A) from 1993 onwards $(n=236)$ and prevalent and incident cases (Hospital cohort B) diagnosed between 1974 and $1992(n=148)$. We reviewed all medical records of patients with hyperprolactinemia. The patients were included if they met the following criteria: elevated PRL levels and a visible pituitary adenoma at radiological examination corresponding with a prolactinoma. Patients with nontumoral or secondary hyperprolactinemia were excluded. In addition, two patients with malignant prolactinomas were excluded. Sixty-nine percent of the patients had a microadenoma (maximal tumor diameter $<10 \mathrm{~mm}$ ) at diagnosis and the remaining patients a macroadenoma $(\geq 10 \mathrm{~mm})$. Median PRL levels at diagnosis were 87 (interquartile range (IQR) 59-130) $\mu \mathrm{g} / \mathrm{l}$ in microprolactinomas and 1000 (IQR 400-2911) $\mu \mathrm{g} / \mathrm{l}$ in macroprolactinomas. A majority of the patients (88\%) had a normalized PRL level at follow-up. The healthcare system in Sweden is almost entirely financed by taxes and therefore the patient population is regarded as unselected. However, being a specialized clinic might potentially lead to enrolment of patients with higher PRL levels and larger tumors.

Register cohort We used the National Patient Register to identify all patients with a main or secondary diagnosis of hyperprolactinemia using the ninth revision of the International Classification of Diseases (ICD) (ICD-9: code 253.1) from 1987 to 1995. Before 1987, it was not possible to exclusively identify patients with hyperprolactinemia via the use of ICD-8, and after 1995, we assumed that the majority of prolactinoma patients were diagnosed as outpatients. In total, 682 individuals fulfilled these criteria. We excluded 66 patients who were already included in the Hospital cohort and 31 patients with a concomitant diagnosis of acromegaly (ICD-9: 253.0), leaving a final sample of 585 individuals for the analysis.

Comparison cohort For each patient with hyperprolactinemia, we used the Register of Population to identify ten individuals (comparison subjects), matched by sex, birth year and county of residence. The comparison subjects were alive on January 1 , in the year of diagnosis of the corresponding case. Seventy-two comparison subjects were unidentifiable or died between the date of selection and start of follow-up and were therefore omitted from the study, leaving 9618 comparison subjects for the analysis.

Follow-up In this matched cohort study, we have the exposed individuals (those who have hyperprolactinemia) which we will refer to as patients and the unexposed individuals which we will refer to as comparison subjects. By linking data to the Swedish Cancer Register, we ascertained all malignant tumors in patients and comparison subjects. At the time of linkage, Cancer Register data were available through 2007. The follow-up was started at the date of hyperprolactinemia diagnosis in the National Patient Register or the year of prolactinoma diagnosis in the Hospital cohort A. Patients who were likely to be prevalent (Hospital cohort B) entered follow-up on January 1, 1993 because potential cohort subjects that died before that date could have been missed, which would introduce selection on survival. The date of entry for comparison subjects was matched with the date of entry for the respective index case. Follow-up continued until death, cancer diagnosis or December 31, 2007, whichever occurred first. When we calculated risk for all cancers, the diagnosis of first cancer or death was used as the individual endpoint of follow-up. When analyzing specified cancer forms, the follow-up ended at diagnosis of that specific cancer or death. The study was 
approved by the Stockholm Regional Ethics Review Board.

\section{Statistical analysis}

Although our cohort is large relative to other cohorts of prolactinoma patients, we lacked statistical power to detect nothing more than a strongly increased risk of cancer, especially for the less common tumor types. Therefore, we narrowed down the number of hypothesis tests to a minimum, focusing instead on common tumor types and groups of tumors. The risk of cancer in the patient group was compared with that of the comparison subjects by Cox proportional hazards regression. When assessing overall cancer risk, the population was restricted to persons without a cancer diagnosis before the start of follow-up. When studying specific cancer forms, the population was restricted to persons without a history of cancer for that specific form. The time scale for the analysis is time since entry into the respective cohorts. The analysis is conditioned according to the matching variables, implying control for attained age, calendar time, and region. Results are presented as hazard ratios (HRs) with 95\% confidence intervals (CIs) for the relative risk of the different cancer types. When presenting age at diagnosis and duration of follow-up mean ( \pm s.D.) was used. All analyses were performed by SAS version 9.2 (SAS Institute, Inc., Cary, NC, USA).

\section{Results}

Characteristics of the hyperprolactinemia patients are described in Table 1. A majority of the patients were females $(69 \%)$. The mean age at first recorded diagnosis

Table 1 Descriptive characteristics of the hyperprolactinemia cohort.

\begin{tabular}{lc}
\hline & $\begin{array}{c}\text { Hyperprolactinemia patients } \\
n(\%)^{\mathrm{a}}\end{array}$ \\
\hline$n$ & 969 \\
Gender & \\
Female & $668(68.9)$ \\
Male & $301(31.1)$ \\
Age at diagnosis (years) & \\
-24 & $144(14.9)$ \\
$25-34$ & $252(26.0)$ \\
$35-44$ & $214(22.1)$ \\
$45-54$ & $162(16.7)$ \\
$55-64$ & $85(8.8)$ \\
$65+$ & $112(11.6)$ \\
Period of diagnosis & $36(3.7)$ \\
$1974-1979$ & $346(35.7)$ \\
$1980-1989$ & $490(50.6)$ \\
$1990-1999$ & $97(10.0)$ \\
$2000-2005$ & \\
Hyperprolactinemia patient & \\
category & $384(39.6)$ \\
Hospital cohort & $585(60.4)$ \\
Register cohort &
\end{tabular}

${ }^{a}$ Non-additivity to $100 \%$ is due to rounding errors.
Table 2 Malignant tumors before hyperprolactinemia diagnosis in patients and comparison subjects.

\begin{tabular}{lcc}
\hline & \multicolumn{2}{c}{ Observed cancer $(n)$} \\
\cline { 2 - 3 } Cancer site (ICD-7) & $\begin{array}{c}\text { Hyperprolactinemia } \\
\text { patients } \\
(n=969)\end{array}$ & $\begin{array}{c}\text { Comparison } \\
\text { subjects } \\
(n=9618)\end{array}$ \\
\hline All cancer (140-209) & 40 & 191 \\
Upper GI (140-151) & 5 & 6 \\
Lower GI (153, 154) & 6 & 23 \\
Lung (161-163) & 2 & 8 \\
Breast (170) & 4 & 39 \\
Cervix (171) & 3 & 5 \\
Corpus uteri (172) & 1 & 6 \\
Ovarial (175) & 0 & 3 \\
Prostate (177) & 5 & 21 \\
Hematopoietic (200-209) & 3 & 16 \\
\hline
\end{tabular}

ICD, international classification of diseases; GI, gastrointestinal.

of hyperprolactinemia in all patients was $40.8( \pm 16.4)$ years. On average, the 969 patients with hyperprolactinemia were followed for $13.2( \pm 5.3)$ years and the 9618 comparison subjects for $13.9( \pm 4.9)$ years, yielding 12822 and 134099 accumulated personyears of follow-up respectively.

Before the diagnosis of hyperprolactinemia, 40 cases of cancer were observed in the patients and 191 cases in the comparison subjects: the numbers and types of malignant tumor are given in Table 2. In particular, cancer of the cervix and the upper gastrointestinal (GI) system were more prevalent in the hyperprolactinemia patients than in the comparison population.

During follow-up, we identified 73 malignant tumors in the patients and 660 tumors in the comparison subjects in the Cancer Registry (Table 3), corresponding to an overall HR of 1.31 (95\% CI: 1.02-1.68), which was mainly attributable to an increased tumor risk in females ( $P$ for homogeneity between sexes, 0.020). Twelve patients with breast cancer were identified during follow-up in female patients (HR 1.09; 95\% CI: 0.60-1.99) and none in male patients. Five prostate cancers were diagnosed in the patients during followup, which can be compared with 136 cases in the comparison subjects, corresponding to a HR of prostate cancer of 0.40 (95\% CI: 0.16-0.99). A significantly increased risk of upper GI cancer (HR 3.69; 95\% CI: 1.70-8.03) was found in the hyperprolactinemia population, as well as when women and men were analyzed separately (Table 3 ). In the patient cohort, five of nine patients had head and neck cancers, whereas in the comparison subjects 11 of 27 cases were head and neck tumors. Furthermore, increased risk of hematopoietic cancer was found in women (HR 3.51; 95\% CI: 1.06-11.6). Four of five $(80 \%)$ hematopoietic cancers were non-Hodgkin lymphomas (NHL) in the patients, whereas 14 of $42(33 \%)$ were NHL in the comparison subjects. Exclusion of the 1st year of follow-up did not substantially change the estimates. We also analyzed the relative risk of cancer in the hospital cohort and 
Table 3 Hazard ratios $\left(\mathrm{HRs}^{\mathrm{a}}\right)$ for the relative risks of cancer associated with hyperprolactinemia (HPL) in Sweden.

\begin{tabular}{|c|c|c|c|c|c|c|c|c|c|}
\hline \multirow[b]{3}{*}{ Cancer site (ICD-7) } & \multicolumn{9}{|c|}{ No. of observed cancers } \\
\hline & \multicolumn{3}{|c|}{ All patients ${ }^{b}$} & \multicolumn{3}{|c|}{ Register cohort ${ }^{\mathrm{C}}$} & \multicolumn{3}{|c|}{ Hospital cohort $^{d}$} \\
\hline & $\begin{array}{c}\mathrm{HPL} \\
(n=969)\end{array}$ & $\begin{array}{c}\text { CS } \\
(n=9618)\end{array}$ & $\begin{array}{c}\mathrm{HR} \\
(95 \% \mathrm{Cl})\end{array}$ & $\begin{array}{c}\text { HPL } \\
(n=585)\end{array}$ & $\begin{array}{c}\text { CS } \\
(n=5827)\end{array}$ & $\begin{array}{c}\mathrm{HR} \\
(95 \% \mathrm{Cl})\end{array}$ & $\begin{array}{c}\mathrm{HPL} \\
(n=384)\end{array}$ & $\begin{array}{c}\text { CS } \\
(n=3791)\end{array}$ & $\begin{array}{c}\mathrm{HR} \\
(95 \% \mathrm{Cl})\end{array}$ \\
\hline \multicolumn{10}{|l|}{ All cancer (140-209) } \\
\hline All & 73 & 660 & $1.31(1.02-1.68)$ & 55 & 486 & $1.48(1.11-1.98)$ & 18 & 174 & $0.98(0.60-1.60)$ \\
\hline Female & 45 & 317 & $1.72(1.25-2.36)$ & 34 & 229 & $1.92(1.33-2.79)$ & 11 & 88 & $1.30(0.69-2.44)$ \\
\hline Male & 28 & 343 & $0.94(0.63-1.40)$ & 21 & 257 & $1.06(0.67-1.69)$ & 7 & 86 & $0.70(0.32-1.53)$ \\
\hline \multicolumn{10}{|l|}{ Upper GI (140-151) } \\
\hline All & 9 & 27 & $3.69(1.70-8.03)$ & 7 & 21 & $3.87(1.59-9.42)$ & 2 & 6 & $3.20(0.65-15.9)$ \\
\hline Female & 4 & 8 & $5.34(1.56-18.3)$ & 4 & 4 & $12.4(2.77-55.3)$ & 0 & 4 & \\
\hline \multirow{2}{*}{\multicolumn{10}{|c|}{ Lower GI $(153,154)$}} \\
\hline & & & & & & & & & \\
\hline All & 12 & 89 & $1.67(0.89-3.12)$ & 10 & 70 & $1.94(0.97-3.90)$ & 2 & 19 & $0.99(0.23-4.28)$ \\
\hline Female & 6 & 35 & $2.36(0.96-5.81)$ & 4 & 27 & $2.21(0.74-6.63)$ & 2 & 8 & $2.72(0.56-13.1)$ \\
\hline Male & 6 & 54 & $1.28(0.53-3.06)$ & 6 & 43 & $1.79(0.73-4.41)$ & 0 & 11 & \\
\hline \multicolumn{10}{|l|}{ Lung (161-163) } \\
\hline All & 3 & 64 & $0.49(0.15-1.56)$ & 3 & 49 & $0.67(0.21-2.16)$ & 0 & 15 & \\
\hline Female & 2 & 28 & $0.81(0.19-3.44)$ & 2 & 21 & $1.09(0.25-4.74)$ & 0 & 7 & \\
\hline Male & 1 & 36 & $0.27(0.04-1.97)$ & 1 & 28 & $0.37(0.05-2.77)$ & 0 & 8 & \\
\hline \multicolumn{10}{|l|}{ Breast (170) } \\
\hline Female & 12 & 118 & $1.09(0.60-1.99)$ & 8 & 75 & $1.24(0.59-2.60)$ & 4 & 43 & $0.88(0.32-2.45)$ \\
\hline Male & 0 & 1 & & 0 & 1 & & 0 & 0 & \\
\hline Cervix (171) & 3 & 9 & $3.51(0.93-13.3)$ & 2 & 7 & $3.14(0.63-15.6)$ & 1 & 2 & $4.63(0.42-51.3)$ \\
\hline Corpus uteri (172) & 4 & 26 & $2.25(0.76-6.70)$ & 1 & 19 & $0.87(0.11-6.71)$ & 3 & 7 & $4.82(1.20-19.3)$ \\
\hline Ovarial (175) & 2 & 18 & $1.22(0.28-5.35)$ & 2 & 14 & $1.64(0.36-7.40)$ & 0 & 4 & \\
\hline Prostate (177) & 5 & 136 & $0.40(0.16-0.99)$ & 2 & 95 & $0.27(0.07-1.10)$ & 3 & 41 & $0.61(0.19-1.98)$ \\
\hline \multicolumn{10}{|c|}{ Hematopoietic (200-209) } \\
\hline All & 5 & 42 & $1.81(0.68-4.81)$ & 5 & 32 & $3.10(1.09-8.82)$ & 0 & 10 & \\
\hline Female & 4 & 16 & $3.51(1.06-11.6)$ & 4 & 12 & $6.00(1.56-23.0)$ & 0 & 4 & \\
\hline Male & 1 & 26 & $0.64(0.08-4.85)$ & 1 & 20 & $1.12(0.14-8.95)$ & 0 & 6 & \\
\hline
\end{tabular}

ICD, international classification of diseases; $\mathrm{Cl}$, confidence interval; $\mathrm{Gl}$, gastrointestinal; $\mathrm{CS}$, comparison subjects.

aBold type: $95 \% \mathrm{Cl}$ does not include 1.00 .

${ }^{\mathrm{b}}$ Based on 12822 person-years in the patients and 134099 person-years in the comparison subjects.

${ }^{\mathrm{C}}$ Based on 8577 person-years in the patients and 92294 person-years in the comparison subjects.

${ }^{\mathrm{d}}$ Based on 4244 person-years in the patients and 41805 person-years in the comparison subjects.

register cohort separately, where the overall cancer risk remained significantly increased only in the register cohort (Table 3). In the smaller hospital-based cohort the increased risk of upper GI cancer in men remained, though with low precision (HR 9.74; 95\% CI: 1.37-69.2).

\section{Discussion}

We found a small, but significant, increase in overall cancer risk in hyperprolactinemia patients after diagnosis compared with matched individuals from the general population. This overall increased risk of cancer in hyperprolactinemia patients was mainly attributed to an increased risk of upper GI and hematopoietic cancer. To the best of our knowledge, so far, only one cohort study has evaluated the overall cancer risk in prolactinoma patients (24), where no increased risk of neoplasia was observed. However, that study consisted of a small number of patients $(n=98)$ and average follow-up was only 3.6 years.

The strengths of our study are the relatively large sample size and the extended follow-up time.
Information was retrieved from the Swedish Cancer Registry, which covers the whole country and provides complete and high-quality population-based data (23). In this study, the patient cohort was partly made up of a well-characterized hospital cohort recruited from a specific catchment area. To increase the number of patients we also identified patients via the National Patient Register. A potential concern with reference to the latter group is the specificity of the hyperprolactinemia diagnosis. Acromegaly has been associated with increased risk of colorectal adenomas and cancer and also possibly other neoplasms (25). Approximately, onethird of the patients with acromegaly have elevated PRL levels (26), we therefore excluded patients with a concomitant diagnosis of acromegaly. Furthermore, one potential bias might be that hyperprolactinemia patients are subjected to regular clinical follow-up, a fact that may have resulted in earlier tumor diagnosis, at least in some cases, compared with controls. In addition, patients hospitalized for hyperprolactinemia may have other comorbidities or exposures increasing the risk of cancer. Apart from the matching variables, we were not able to adjust for other factors associated 
with risk of cancer, such as smoking, alcohol consumption, or body mass index. In addition, we cannot exclude the effect of any unmeasured potential confounding factors. Finally, although our study is one of the largest to date evaluating risk of cancer in hyperprolactinemia patients, the sample size provides only limited statistical power to detect rare outcomes, such as cancer.

The concerns regarding hyperprolactinemia and cancer risk in humans have so far mainly been attributed to the possible tumor growth-promoting activity of PRL on breast and prostate tissue (27). In this study, however, we did not find any increased risk of breast cancer, an observation in agreement with a recent study by Dekkers et al. (12) who found that the relative risk of breast cancer in 1342 patients with treated hyperprolactinemia was 1.07 (95\% CI: 0.50-2.03). Nevertheless, it is prudent to consider that the number of breast cancer cases in our study is low and our data alone does not preclude an increased risk of breast cancer. Moreover, it could be speculated that PRL stimulates growth of breast neoplasia, but suppresses tumorigenesis through a reduction in estrogen, which is a well-established risk factor of breast cancer (28). Furthermore, due to the limited set of variables recorded in the in-patient register, we were not able to adjust for potential confounders regarding breast cancer risk such as family history, estrogen treatment, reproductive history, and body mass index.

In in vitro and animal studies, PRL has been shown to stimulate proliferation of prostate cells $(13,29)$ and to stimulate growth of the prostate (14). Furthermore, transgenic mice overexpressing the PRL gene, develop prostate hyperplasia (30); however, the generalizability to humans is unclear. In a prospective case-control study, PRL levels were measured in 144 men with prostate cancer and 289 male controls, where no association was found between PRL levels and prostate cancer (16). Furthermore, the effect of hyperprolactinemia on human prostate was evaluated in 20 men with prolactinomas, demonstrating a reduced prostate size compared with controls (31). The authors speculate that this finding is probably due to reduced testosterone and dihydrotestosterone levels found in the prolactinoma patients (31). This study is the first to report a reduced risk of prostate cancer in hyperprolactinemia patients. Elevated PRL levels to hypogonadism by interfering with pulsatile GNRH release (32). The reduced risk of prostate cancer in our cohort might therefore, in addition to chance variation, be attributed to a history of low androgen exposure (33). Androgen status is regularly followed in male patients with hyperprolactinemia and if testosterone levels do not normalize, androgen replacement therapy might be introduced. In such cases prostate-specific antigen levels may be followed regularly, potentially resulting in increased detection of early prostate cancer (34). Such vigilance would bias the estimates toward a higher incidence of prostate cancer in the patient cohort and thus would not explain our finding of a reduced risk.

We found an increased risk of upper GI cancer in the entire cohort but also in women and men in the stratified analysis. The cancers in the hyperprolactinemia patients mainly constituted of head and neck cancers, whereas in the comparison group a majority of the patients had cancer in the esophagus or stomach. Even before the hyperprolactinemia diagnosis, there were more hyperprolactinemic patients than expected with upper GI cancer, and again, with a preponderance for head and neck cancers. This finding is both unexpected and intriguing and the mechanism is obscure and should thus be interpreted with extra caution. Bhatavdekar et al. (19) demonstrated that patients with advanced tongue cancer had higher PRL levels compared with controls and that PRL in a multivariate analysis was an independent prognostic risk factor of survival, indicating that PRL is produced by the tumors and might act as a local growth promoter. We lack information on major risk factors for head and neck cancer, such as smoking and alcohol (35), to explore this association further. However, we found a slightly reduced lung cancer risk in the entire patient cohort, indicating no excess smoking, if anything, the contrary is true.

Another intriguing finding was the elevated risk for hematopoietic cancer observed in women, although it is important to note the low number of cases and wide CIs. PRL has been recognized to be important in the maturation and functional maintenance of the immune system (36). PRL receptors are expressed by virtually all subtypes of immune cells, whereas PRL is produced mainly by lymphocytes (37). Experimental data indicate that PRL promotes lymphocyte proliferation (38) and has anti-apoptotic effects on lymphoid cells (39). In addition, human cell lines of B-lymphoblastoid cells (40) and NHL cells (41) produce PRL. Furthermore, elevated serum PRL levels have been observed in patients with acute myeloid leukemia (20) and in advanced multiple myeloma, where PRL concentrations increased during disease progression (21). If the increased risk of hematopoietic cancers observed in the hyperprolactinemia women is by chance or is to some extent due to a stimulatory effect of PRL remains elusive.

The relevance of PRL and cancer risk in patients receiving antipsychotics is unclear. There are reports of an increased breast cancer risk in dopamine antagonist treated patients (42); however, there are contradictory findings (43). The vast majority of hyperprolactinemia patients are treated with dopamine agonists. Little is known about the potential influence of dopamine agonist treatment and cancer risk. However, in patients with Parkinson's disease, often treated with high doses of dopamine agonists, a recent meta-analysis evaluating cancer risk in these patients, showed significantly reduced cancer risk ratios (44).

In conclusion, this study is the first of its kind to indicate that hyperprolactinemia patients have a small 
increased overall cancer risk compared with a comparison group. This increased cancer risk was mainly attributed to augmented risk of upper GI and hematopoietic cancers. We found no increased risk of breast cancer in women and a reduced risk of prostate cancer in men. Although this is one of the largest hyperprolactinemia cohorts to date, low numbers of cancer cases preclude definitive conclusions and therefore our results need to be confirmed by larger studies. Still, our findings suggest that further investigations into the potential association between PRL and different cancer forms are warranted. In addition, these findings may stress the importance of an active treatment strategy and close follow-up of hyperprolactinemia patients.

\section{Declaration of interest}

The authors declare that there is no conflict of interest that could be perceived as prejudicing the impartiality of the research reported.

\section{Funding}

This work was supported by a grant from Elin Danielsson foundation, Sweden.

\section{References}

1 Ben-Jonathan N, Mershon JL, Allen DL \& Steinmetz RW. Extrapituitary prolactin: distribution, regulation, functions, and clinical aspects. Endocrine Reviews 199617 639-669. (doi:10. 1210/edrv-17-6-639)

2 Daly AF, Rixhon M, Adam C, Dempegioti A, Tichomirowa MA \& Beckers A. High prevalence of pituitary adenomas: a crosssectional study in the province of Liege, Belgium. Journal of Clinical Endocrinology and Metabolism 200691 4769-4775. (doi:10. 1210/jc.2006-1668)

3 Casanueva FF, Molitch ME, Schlechte JA, Abs R, Bonert V, Bronstein MD, Brue T, Cappabianca P, Colao A, Fahlbusch R, Fideleff H, Hadani M, Kelly P, Kleinberg D, Laws E, Marek J, Scanlon M, Sobrinho LG, Wass JA \& Giustina A. Guidelines of the Pituitary Society for the diagnosis and management of prolactinomas. Clinical Endocrinology 200665 265-273. (doi:10.1111/j. 1365-2265.2006.02562.x)

4 Delgrange E, Trouillas J, Maiter D, Donckier J \& Tourniaire J. Sexrelated difference in the growth of prolactinomas: a clinical and proliferation marker study. Journal of Clinical Endocrinology and Metabolism 199782 2102-2107. (doi:10.1210/jc.82.7.2102)

5 Liby K, Neltner B, Mohamet L, Menchen L \& Ben-Jonathan N. Prolactin overexpression by MDA-MB-435 human breast cancer cells accelerates tumor growth. Breast Cancer Research and Treatment 200379 241-252. (doi:10.1023/A:1023956223037)

6 Welsch CW, Louks G, Fox D \& Brooks C. Enhancement by prolactin of carcinogen induced mammary cancerigenesis in the male rat. British Journal of Cancer 197532 427-431. (doi:10.1038/bjc. 1975.243)

7 Strungs I, Gray RA, Rigby HB \& Strutton G. Two case reports of breast carcinoma associated with prolactinoma. Pathology 1997 29 320-323. (doi:10.1080/00313029700169205)

8 Haga S, Watanabe O, Shimizu T, Iida T, Imamura H, Kajiwara T \& Fujibayashi M. Breast cancer in a male patient with prolactinoma. Surgery Today 199323 251-255. (doi:10.1007/BF00309236)

9 Forloni F, Giovilli M, Pecis C, Bortolani E, Preziosi A, Barzaghi ME, Corti D \& Beck-Peccoz P. Pituitary prolactin-secreting macroadenoma combined with bilateral breast cancer in a 45 -year-old male. Journal of Endocrinological Investigation 200124 454-459.
10 Tworoger SS, Eliassen AH, Rosner B, Sluss P \& Hankinson SE. Plasma prolactin concentrations and risk of postmenopausal breast cancer. Cancer Research 200464 6814-6819. (doi:10. 1158/0008-5472.CAN-04-1870)

11 Tworoger SS, Eliassen AH, Sluss P \& Hankinson SE. A prospective study of plasma prolactin concentrations and risk of premenopausal and postmenopausal breast cancer. Journal of Clinical Oncology 200725 1482-1488. (doi:10.1200/JCO.2006.07. 6356)

12 Dekkers OM, Romijn JA, de Boer A \& Vandenbroucke JP. The risk for breast cancer is not evidently increased in women with hyperprolactinemia. Pituitary 201013 195-198. (doi:10.1007/ s11102-009-0214-y)

13 Crepin A, Bidaux G, Vanden-Abeele F, Dewailly E, Goffin V, Prevarskaya N \& Slomianny C. Prolactin stimulates prostate cell proliferation by increasing endoplasmic reticulum content due to SERCA 2b over-expression. Biochemical Journal 2007401 49-55. (doi:10.1042/BJ20060870)

14 Negro-Vilar A, Saad WA \& McCann SM. Evidence for a role of prolactin in prostate and seminal vesicle growth in immature male rats. Endocrinology 1977100 729-737. (doi:10.1210/endo-1003-729)

15 Hsing AW \& Comstock GW. Serological precursors of cancer: serum hormones and risk of subsequent prostate cancer. Cancer Epidemiology, Biomarkers and Prevention 19932 27-32.

16 Stattin P, Rinaldi S, Stenman UH, Riboli E, Hallmans G, Bergh A \& Kaaks R. Plasma prolactin and prostate cancer risk: a prospective study. International Journal of Cancer 200192 463-465. (doi:10. 1002/ijc.1191)

17 Levina VV, Nolen B, Su Y, Godwin AK, Fishman D, Liu J, Mor G, Maxwell LG, Herberman RB, Szczepanski MJ, Szajnik ME, Gorelik E \& Lokshin AE. Biological significance of prolactin in gynecologic cancers. Cancer Research 200969 5226-5233. (doi:10.1158/ 0008-5472.CAN-08-4652)

18 Bhatavdekar JM, Patel DD, Chikhlikar PR, Shah NG, Vora HH, Ghosh N \& Trivedi TI. Ectopic production of prolactin by colorectal adenocarcinoma. Diseases of the Colon and Rectum $20014 \mathbf{4}$ 119-127. (doi:10.1007/BF02234833)

19 Bhatavdekar JM, Patel DD, Vora HH, Shah NG, Chikhlikar PR \& Ghosh N. Prolactin as a local growth promoter in patients with locally advanced tongue cancer: GCRI experience. Head and Neck 200022 257-264. (doi:10.1002/(SICI) 1097-0347(200005)22: $3<257::$ AID-HED8 > 3.0.CO;2-K)

20 Hatfill SJ, Kirby R, Hanley M, Rybicki E \& Bohm L. Hyperprolactinemia in acute myeloid leukemia and indication of ectopic expression of human prolactin in blast cells of a patient of subtype M4. Leukemia Research 199014 57-62. (doi:10.1016/01452126(90)90146-Z)

21 Gado K, Rimanoczi E, Hasitz A, Gigler G, Toth BE, Nagy GM, Paloczi K \& Domjan G. Elevated levels of serum prolactin in patients with advanced multiple myeloma. Neuroimmunomodulation 20019 231-236. (doi:10.1159/000049031)

22 Ludvigsson JF, Otterblad-Olausson P, Pettersson BU \& Ekbom A. The Swedish personal identity number: possibilities and pitfalls in healthcare and medical research. European Journal of Epidemiology 200924 659-667. (doi:10.1007/s10654-009-9350-y)

23 Barlow L, Westergren K, Holmberg L \& Talback M. The completeness of the Swedish Cancer Register: a sample survey for year 1998. Acta Oncologica 200948 27-33. (doi:10.1080/ $02841860802247664)$

24 Popovic V, Damjanovic S, Micic D, Nesovic M, Djurovic M, Petakov M, Obradovic S, Zoric S, Simic M, Penezic Z \& Marinkovic J. Increased incidence of neoplasia in patients with pituitary adenomas. The Pituitary Study Group. Clinical Endocrinology 199849 441-445. (doi:10.1046/j.1365-2265.1998.00536.x)

25 Jenkins PJ. Cancers associated with acromegaly. Neuroendocrinology 200683 218-223. (doi:10.1159/000095531)

26 Franks S, Jacobs HS \& Nabarro JD. Prolactin concentrations in patients with acromegaly: clinical significance and response to surgery. Clinical Endocrinology 19765 63-69. (doi:10.1111/j. 1365-2265.1976.tb03804.x) 
27 Goffin V, Bernichtein S, Touraine P \& Kelly PA. Development and potential clinical uses of human prolactin receptor antagonists. Endocrine Reviews 200526 400-422. (doi:10.1210/er.20040016)

28 Veronesi U, Boyle P, Goldhirsch A, Orecchia R \& Viale G. Breast cancer. Lancet $2005 \mathbf{3 6 5}$ 1727-1741. (doi:10.1016/S01406736(05)66546-4)

29 Nevalainen MT, Valve EM, Ingleton PM, Nurmi M, Martikainen PM \& Harkonen PL. Prolactin and prolactin receptors are expressed and functioning in human prostate. Journal of Clinical Investigation 199799 618-627. (doi:10.1172/ JCI119204)

30 Wennbo H, Kindblom J, Isaksson OG \& Tornell J. Transgenic mice overexpressing the prolactin gene develop dramatic enlargement of the prostate gland. Endocrinology $1997 \mathbf{1 3 8} 4410-4415$. (doi:10.1210/en.138.10.4410)

31 Colao A, Vitale G, Di Sarno A, Spiezia S, Guerra E, Ciccarelli A \& Lombardi G. Prolactin and prostate hypertrophy: a pilot observational, prospective, case-control study in men with prolactinoma. Journal of Clinical Endocrinology and Metabolism 200489 2770-2775. (doi:10.1210/jc.2003-032055)

32 Bouchard P, Lagoguey M, Brailly S \& Schaison G. Gonadotropinreleasing hormone pulsatile administration restores luteinizing hormone pulsatility and normal testosterone levels in males with hyperprolactinemia. Journal of Clinical Endocrinology and Metabolism 198560 258-262. (doi:10.1210/jcem-60-2-258)

33 Gann PH, Hennekens CH, Ma J, Longcope C \& Stampfer MJ. Prospective study of sex hormone levels and risk of prostate cancer. Journal of the National Cancer Institute $1996 \mathbf{8 8} 1118-1126$. (doi:10.1093/jnci/88.16.1118)

34 Schroder FH, Hugosson J, Roobol MJ, Tammela TL, Ciatto S, Nelen V, Kwiatkowski M, Lujan M, Lilja H, Zappa M, Denis LJ, Recker F, Berenguer A, Maattanen L, Bangma CH, Aus G, Villers A, Rebillard X, van der Kwast T, Blijenberg BG, Moss SM, de Koning HJ \& Auvinen A. Screening and prostate-cancer mortality in a randomized European study. New England Journal of Medicine 2009360 1320-1328. (doi:10.1056/NEJMoa0810084)

35 Rosenquist K, Wennerberg J, Schildt EB, Bladstrom A, Hansson BG \& Andersson G. Use of Swedish moist snuff, smoking and alcohol consumption in the aetiology of oral and oropharyngeal squamous cell carcinoma. A population-based case-control study in Southern Sweden. Acta Otolaryngologica 2005125 991-998. (doi:10.1080/00016480510043440)

36 Bole-Feysot C, Goffin V, Edery M, Binart N \& Kelly PA. Prolactin (PRL) and its receptor: actions, signal transduction pathways and phenotypes observed in PRL receptor knockout mice. Endocrine Reviews 199819 225-268. (doi:10.1210/er.19.3.225)

37 Montgomery DW. Prolactin production by immune cells. Lupus 200110 665-675. (doi:10.1191/096120301717164895)

38 Clevenger CV, Altmann SW \& Prystowsky MB. Requirement of nuclear prolactin for interleukin-2 - stimulated proliferation of T lymphocytes. Science $1991 \mathbf{2 5 3}$ 77-79. (doi:10.1126/ science.2063207)

39 Al-Sakkaf KA, Mooney LM, Dobson PR \& Brown BL. Possible role for protein kinase $B$ in the anti-apoptotic effect of prolactin in rat $\mathrm{Nb} 2$ lymphoma cells. Journal of Endocrinology 2000167 85-92. (doi:10.1677/joe.0.1670085)

40 DiMattia GE, Gellersen B, Bohnet HG \& Friesen HG. A human B-lymphoblastoid cell line produces prolactin. Endocrinology 1988 122 2508-2517. (doi:10.1210/endo-122-6-2508)

41 Matera L, Geuna M, Pastore C, Buttiglieri S, Gaidano G, Savarino A, Marengo S \& Vonderhaar BK. Expression of prolactin and prolactin receptors by non-Hodgkin's lymphoma cells. International Journal of Cancer $2000 \mathbf{8 5}$ 124-130. (doi:10.1002/ (SICI)1097-0215(20000101)85:1<124::AID-IJC22>3.0.CO;2-U)

42 Wang PS, Walker AM, Tsuang MT, Orav EJ, Glynn RJ, Levin R \& Avorn J. Dopamine antagonists and the development of breast cancer. Archives of General Psychiatry 200259 1147-1154. (doi:10.1001/archpsyc.59.12.1147)

43 Dalton SO, Johansen C, Poulsen AH, Norgaard M, Sorensen HT, McLaughlin JK, Mortensen PB \& Friis S. Cancer risk among users of neuroleptic medication: a population-based cohort study. British Journal of Cancer 200695 934-939. (doi:10.1038/sj.bjc.6603259)

44 Bajaj A, Driver JA \& Schernhammer ES. Parkinson's disease and cancer risk: a systematic review and meta-analysis. Cancer Causes and Control 201021 697-707. (doi:10.1007/s10552-009-9497-6)

Received 20 April 2011

Accepted 19 May 2011 